\title{
Production and regulation of potato-scab-inducing phytotoxins by Streptomyces scabies
}

\author{
Martin J. Babcock, ${ }^{1}$ Eric C. Eckwall ${ }^{2}$ and Janet L. Schottel ${ }^{1,3 *}$ \\ Department of Biochemistry, ${ }^{1}$ Department of Plant Pathology ${ }^{2}$ and the Plant Molecular Genetics Institute, ${ }^{3}$ University \\ of Minnesota, St Paul, MN 55108, USA
}

(Received 18 November 1992; accepted 10 February 1993)

\begin{abstract}
Phytotoxins with potato-scab-inducing activity were produced by the pathogenic Streptomyces scabies strain RB2 when grown on oatmeal agar medium or in oatmeal broth medium. Five compounds isolated from cell filtrates were identified as thaxtomin compounds $1-5$, previously reported as produced by $S$. scabies grown on potato slices. The optimum temperature for phytotoxin production in oatmeal broth medium was $28{ }^{\circ} \mathrm{C}$. Production of thaxtomin $\mathrm{A}$, the major product, was repressed at least 130-fold when $S$. scabies $\mathrm{RB} 2$ was grown in oatmeal broth medium supplemented with $0.5 \%$ glucose. Thaxtomin A production was also repressed by tryptophan and tyrosine, precursors of which may be involved in feedback inhibition of early steps in biosynthesis. Phytotoxins were secreted by the organism when the cells reached late exponential to early stationary phases of culture growth. The time during growth at which each thaxtomin compound was produced suggests a pathway for the latter steps in thaxtomin biosynthesis.
\end{abstract}

\section{Introduction}

Streptomyces scabies (Lambert \& Loria, 1989) is the causative agent of scab disease on a variety of underground vegetables including radish, beet and potato (Davis \& Garner, 1978). Potato scab adversely affects tuber quality and market value, but not yield (Hooker, 1981; Slack, 1992). Scab lesions vary in colour from brown to black. The morphology of the scab lesion can range in appearance from small raised cork-like tissue around the lenticel to large deep sunken pits up to $7 \mathrm{~mm}$ in depth (Archuleta \& Easton, 1981; Davis \& Garner, 1978; Hooker, 1981).

$S$. scabies infects the tuber through an immature lenticel or a wound site. In response to invasion by the bacterium, suberin is synthesized at the site of infection by cells which lie a few cell layers below the surface of the tuber (Davis \& Garner, 1978; Hooker, 1981). Suberin is the natural protective layer of the tuber, composed of long chain fatty acids, dicarboxylic acids, fatty alcohols and phenolic compounds (Kolattukudy, 1980,1981 ), and is thought to function as a barrier to both moisture loss and microbial attack (Kolattukudy, 1984).

A class of phytotoxins, thaxtomin, has been identified

${ }^{*}$ Author for correspondence. Tel. (612) 6246275 ; fax (612) 625 5780 . which may be involved in infection of the potato by $S$. scabies (Lawrence et al., 1990). Five thaxtomins, designated compounds 1 to 5 , were isolated and purified from a pathogenic strain of $S$. scabies grown on surfacesterilized potato slices (King et al., 1992). Compounds 1 and 4 were previously identified as thaxtomin A and B, respectively (King et al., 1989). Thaxtomins were shown to be unique 4-nitroindol-3-yl-containing 2,5 dioxopiperazines (King et al., 1989, 1992). These purified compounds induce the formation of scab-like lesions when applied to the potato tuber (King et al., 1992), but the mode of action of these compounds is unknown. Analysis of $19 \mathrm{~S}$. scabies isolates demonstrated that pathogenicity was positively correlated with the isolates' ability to produce thaxtomin on potato slices (King et al., 1991), emphasizing the potential importance of these compounds in scab disease.

To study the synthesis of phytotoxins associated with potato scab disease, the ability of $S$. scabies to produce phytotoxins in a synthetic medium was investigated. Phytotoxins were produced by $S$. scabies when grown in an oatmeal medium, and the structures of these compounds were determined. Several factors which affected thaxtomin production were also investigated. The ability to produce thaxtomins in liquid culture has facilitated the production and purification of these compounds and will be valuable in elucidating the pathway for phytotoxin biosynthesis. 


\section{Methods}

Bacterial strain and growth. Streptomyces scabies strain RB2 is a pathogenic isolate obtained from a deep-pitted scab lesion on the potato cultivar Russet Burbank grown in Becker, MN, USA. S. scabies was maintained on oatmeal agar medium (Shirling \& Gottlieb, 1966) and grown at $30^{\circ} \mathrm{C}$. The bacterium was tested for phytotoxin production after growth on MM agar (Hopwood et al., 1985), NMM agar (as in Hopwood et al., 1985, but with the addition of $1.5 \%$ agar, $w / v$, and lacking PEG), Czapek Solution agar (Difco Laboratories) and oatmeal agar. To test whether a potato-specific compound might be necessary to induce phytotoxin production, $4 \%$ (final concentration, $\mathrm{v} / \mathrm{v}$ ) potato-dextrose broth (PDB) was added to MM agar and Czapek Solution agar. PDB was made by autoclaving $200 \mathrm{~g}$ sliced potato per litre of water for $20 \mathrm{~min}$, straining, and adding $20 \mathrm{~g}$ dextrose $\mathrm{l}^{-1}$.

Oatmeal broth medium was prepared by boiling $20 \mathrm{~g}$ oatmeal per litre of water for $20 \mathrm{~min}$. Particulate matter was removed by filtration through cheesecloth, centrifugation at $10000 \mathrm{~g}$ for $10 \mathrm{~min}$, and filtration through Whatman no. 1 paper. Trace elements were added to the oatmeal broth to a final concentration (per litre) of $80 \mu \mathrm{ZnCl}_{2}$, $400 \mu \mathrm{g} \mathrm{FeCl}_{3} .6 \mathrm{H}_{2} \mathrm{O}, 20 \mu \mathrm{g} \mathrm{CuCl}_{3} \cdot 2 \mathrm{H}_{2} \mathrm{O}, 20 \mu \mathrm{g} \mathrm{MnCl}_{2} \cdot 4 \mathrm{H}_{2} \mathrm{O}, 20 \mu \mathrm{g}$ $\mathrm{Na}_{2} \mathrm{~B}_{4} \mathrm{O}_{7} \cdot 10 \mathrm{H}_{2} \mathrm{O}$ and $20 \mu \mathrm{g}\left(\mathrm{NH}_{4}\right)_{6} \mathrm{Mo}_{7} \mathrm{O}_{24} \cdot 4 \mathrm{H}_{2} \mathrm{O}$. Growth in oatmeal broth medium was monitored by following the culture $\mathrm{OD}_{650}$, using uninoculated medium as a blank. Dry cell weight measurements of culture samples were also used to monitor growth and correlated well with the $\mathrm{OD}_{650}$ measurements.

Potato mini-tuber assays. Two methods were used to generate potato mini-tubers for pathogenicity and scab lesion assays. Solanum tuberosum var. Kennebec mother plants were grown from seed pieces in the greenhouse until flowering. Leaf bud cuttings were taken from the mature plant and placed in five-inch pots of steam-sterilized sand (Lauer, 1977). Kennebec minitubers formed within 3-4 weeks. These minitubers were inoculated directly with $S$. scabies spores harvested from oatmeal agar medium with sterile water. Phytotoxin preparations were applied to $6 \mathrm{~mm}$ sterile filter paper discs and air-dried. The sample discs were applied directly to the tubers.

In the second method, sterile plants of Solanum tuberosum var. Pontiac were cultured in test tubes in MS basal medium with $0.4 \%$ agar (Murashige \& Skoog, 1962) and grown in the laboratory under Gro-lux lights (GTE Sylvania). When the plants reached $5 \mathrm{~cm}$ in height they were transferred to trays containing steam-sterilized sand. On days 7 and 21 the plants were fertilized with $1.0 \mathrm{~g}$ of a commercial 20:20:20 $(\mathrm{N}: \mathrm{P}: \mathrm{K})$ soluble fertilizer per 30 plants. After five weeks of growth, five Pontiac plants with attached minitubers were transplanted to a $12.5 \mathrm{~cm}$ diam. clay pot containing steam-sterilized sand. During transplanting, the minitubers were treated either with spores of $S$. scabies or with $20 \mu \mathrm{l}$ phytotoxin dissolved in acetone. Acetone preparations were allowed to dry on the tuber surface before covering with sand. Scab lesions on the potato tuber induced by phytotoxin application were apparent after $24 \mathrm{~h}$ incubation. Lesions induced by spores were visible after $7-10 \mathrm{~d}$.

Phytotoxin isolation. Phytotoxins were extracted from S. scabies grown on agar medium or potato slices and purified by a modification of the procedure of Lawrence et al. (1990). Agar media plates were inoculated with spores of $S$. scabies RB2 and incubated at $30^{\circ} \mathrm{C}$ for $10 \mathrm{~d}$. Surface-sterilized potato slices were inoculated and incubated at room temperature for $10 \mathrm{~d}$. The bacteria, including the agar medium or potato slice, were homogenized in acetone using a Waring blender. The cell debris and medium were removed by filtration, and the acetonesoluble material was dried using a rotary evaporator. Phytotoxins were dissolved in water and extracted three times with an equal vol. chloroform. The chloroform fractions were collected and dried. Phytotoxin was dissolved in acetone to test for biological activity and for further purification.
Phytotoxins were also extracted from cultures of $S$. scabies RB2 grown in oatmeal broth medium. In initial experiments, the cell pellet harvested from the oatmeal broth medium was extracted with an equal vol. acetone. The acetone was evaporated, and the sample was resuspended in water. Both the cell pellet and cell filtrate samples were extracted three times with equal vols chloroform. The chloroform fractions from the cell pellet or cell filtrate were dried under vacuum using a rotary evaporator. Phytotoxin preparations were resuspended in chloroform for analysis by TLC or in acetone for testing scab-lesioninducing activity.

To investigate the timing of production of these compounds, a 21 flask containing $400 \mathrm{ml}$ oatmeal broth medium was inoculated with $S$. scabies $\mathrm{RB} 2$ spores. The culture was incubated at $30^{\circ} \mathrm{C}$ on a rotary shaker. Springs were placed in the flasks to increase aeration. The flask was capped with two milk filters (Kendal Agricultural Products) to aid in oxygen exchange, attached with a rubber band. Bacterial growth was measured as $\mathrm{OD}_{650}$. At various times during growth, $25 \mathrm{ml}$ samples were taken, the cells were removed by filtration through Whatman no. 1 paper, and the cell filtrate was extracted three times with an equal vol. chloroform. The chloroform was evaporated, and the samples were solubilized in chloroform for TLC analysis.

Phytotoxins were purified by silica gel TLC in chloroform/methanol ( $9: 1$, by vol.) and by reverse phase C18 TLC in acetone $/ \mathrm{H}_{2} \mathrm{O}(3: 2$, by vol.) as described in Lawrence et al. (1990). The molecular masses of the five thaxtomin compounds were determined by Fast Atom Bombardment (FAB) mass spectroscopy using a Kratos MS-25 mass spectrometer. NMR spectra were measured for samples dissolved in deuterated methanol with a Nicolet NT-300 WB spectrometer at $300 \mathrm{MHz}$. The spectrum of compound 3 was also measured in deuterated chloroform.

Quantification of thaxtomin A production. Samples were analysed and quantified by HPLC using a Hewlett Packard 1090 with an Alltech Econosil C18 column ( $10 \mu \mathrm{m}$ particle size, $4.6 \times 250 \mathrm{~mm}$ ). Phytotoxins were eluted with a $25-50 \%$ acetonitrile gradient over $20 \mathrm{~min}$ and monitored as $A_{380}$. Purified thaxtomin $\mathrm{A}$ was weighed and a standard solution of $1.0 \mathrm{mg} \mathrm{ml}^{-1}$ was used to establish a standard curve relating $\mu \mathrm{g}$ thaxtomin A to peak area measured at $380 \mathrm{~nm}$ by HPLC. Final amounts of thaxtomin A produced under experimental conditions were reported as $\mathrm{mg}$ thaxtomin $\mathrm{A}$ ( $\mathrm{g}$ cell dry $\mathrm{wt})^{-1}$.

\section{Results}

\section{Phytotoxin production on synthetic agar media}

Six synthetic agar media were chosen to test for phytotoxin production by $S$. scabies. As a positive control for phytotoxin production, $S$. scabies was also grown on surface-sterilized potato slices as reported by Lawrence et al. (1990). Agar media and potato slices were inoculated with $S$. scabies and incubated for $10 \mathrm{~d}$. Phytotoxin was extracted from the media and bacterial lawns and tested for its ability to elicit lesion formation on mini-tubers of Solanum tuberosum var. Kennebec. The results of the lesion testing (Table 1) demonstrated that scab-inducing compounds were produced when $S$. scabies was grown on potato slices or on oatmeal agar medium, but not on the other media used for growth. The assay for scab-inducing activity using Pontiac minitubers yielded similar results (data not shown).

The scab lesions induced by phytotoxins isolated from S. scabies RB2 grown on oatmeal agar were similar to 
Table 1. Lesion formation on Kennebec mini-tubers induced by phytotoxins

\begin{tabular}{lrccc}
\hline \hline & \multicolumn{3}{c}{$\begin{array}{c}\text { Severity of lesions formed } \dagger \\
\text { (no. of mini-tubers) }\end{array}$} \\
\cline { 2 - 5 } Treatment* & - & + & ++ & +++ \\
\hline Oatmeal agar & 1 & 2 & 2 & 15 \\
Czapek agar & 20 & 0 & 0 & 0 \\
Czapek agar + PDB & 20 & 0 & 0 & 0 \\
NMM agar & 20 & 0 & 0 & 0 \\
MM agar & 20 & 0 & 0 & 0 \\
MM agar+PDB & 20 & 0 & 0 & 0 \\
Potato slices & 5 & 9 & 5 & 1 \\
Acetone & 20 & 0 & 0 & 0 \\
Uninoculated oatmeal agar & 20 & 0 & 0 & 0 \\
\hline \hline
\end{tabular}

* Phytotoxins were extracted from $S$. scabies grown on six different media and on potato slices, and applied to the mini-tubers. Acetone and an extract from uninoculated oatmeal agar were used as controls.

† Twenty tubers were used for each treatment and scored for severity of lesion formation as follows: - , healthy tuber; + , dark brown skin or lenticels; ++ , blackened tissue; +++ , blackened and erupted skin.

the lesions induced by pathogen infection (Fig. 1.) The scab symptoms included browning and eruption of the tuber's skin at the site of phytotoxin application. These symptoms were apparent about $24 \mathrm{~h}$ after phytotoxin application and increased in severity over time. The lesions induced by the $S$. scabies spores appeared to be somewhat more severe than the lesions resulting from phytotoxin application. This difference may be due to continual production of phytotoxins by the pathogen at the site of infection.

Control experiments were done to ensure that lesions induced by phytotoxins were due to the activity of the phytotoxin and not to contamination of the soil, tuber or phytotoxin with the pathogen. The scab lesions induced by phytotoxin application were examined for the presence of the pathogen. Sections of the tuber containing a lesion were subcultured on $5 \%(\mathrm{w} / \mathrm{v})$ water agar medium (Harrison, 1962). S. scabies was not recovered from the lesion using this method. Phytotoxin preparations were also inoculated onto oatmeal agar plates, and no evidence of spore contamination was apparent. These results indicate that the scab lesions induced by phytotoxin application were due to phytotoxin activity and not to contamination with $S$. scabies.

To determine the number of compounds produced that had scab-inducing activity, the components of a phytotoxin extract from $S$. scabies grown on oatmeal agar medium were separated by silica gel TLC using chloroform/methanol (9:1). The silica gel TLC plate was fractionated and the compounds were eluted. These samples were dried and suspended in acetone and applied to Kennebec mini-tubers to assay for pathogenicity. (a)

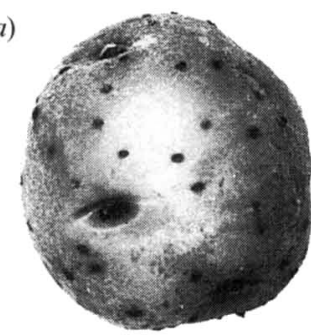

(b)

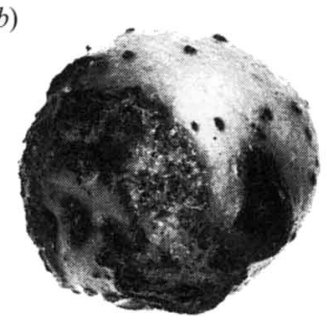

(c)

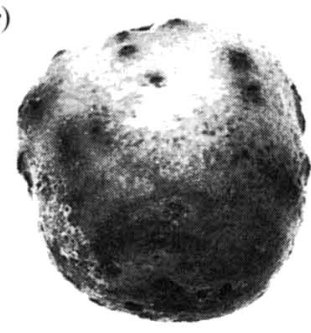

Fig. 1. Scab lesions on Pontiac mini-tubers. Pontiac mini-tubers were treated with $(a)$ acetone, $(b) S$. scabies RB2 spores, or $(c)$ a phytotoxin extract from $S$. scabies RB2 grown in oatmeal broth medium. The darkened areas on the tubers in $(b)$ and $(c)$ correspond to scab lesions.

Only fractions containing yellow compounds possessed scab-inducing activity (data not shown). This is consistent with the yellow-pigmented thaxtomin compounds isolated by Lawrence et al. (1990) from S. scabies grown on sterilized potato slices and suggested that the phytotoxins produced by $S$. scabies on oatmeal medium might be similar to the previously characterized thaxtomins.

\section{Phytotoxin production during growth in oatmeal broth medium}

Production of phytotoxins by S. scabies was studied during growth of the organism in oatmeal broth medium. In initial experiments, both the cell pellet and cell filtrate were extracted and tested for the presence of lesioninducing compounds. Only the culture filtrate contained biological activity, indicating that the phytotoxin was either loosely associated with the mycelial surface or was secreted into the growth medium. As with the phytotoxin preparations from cells grown on oatmeal agar medium 

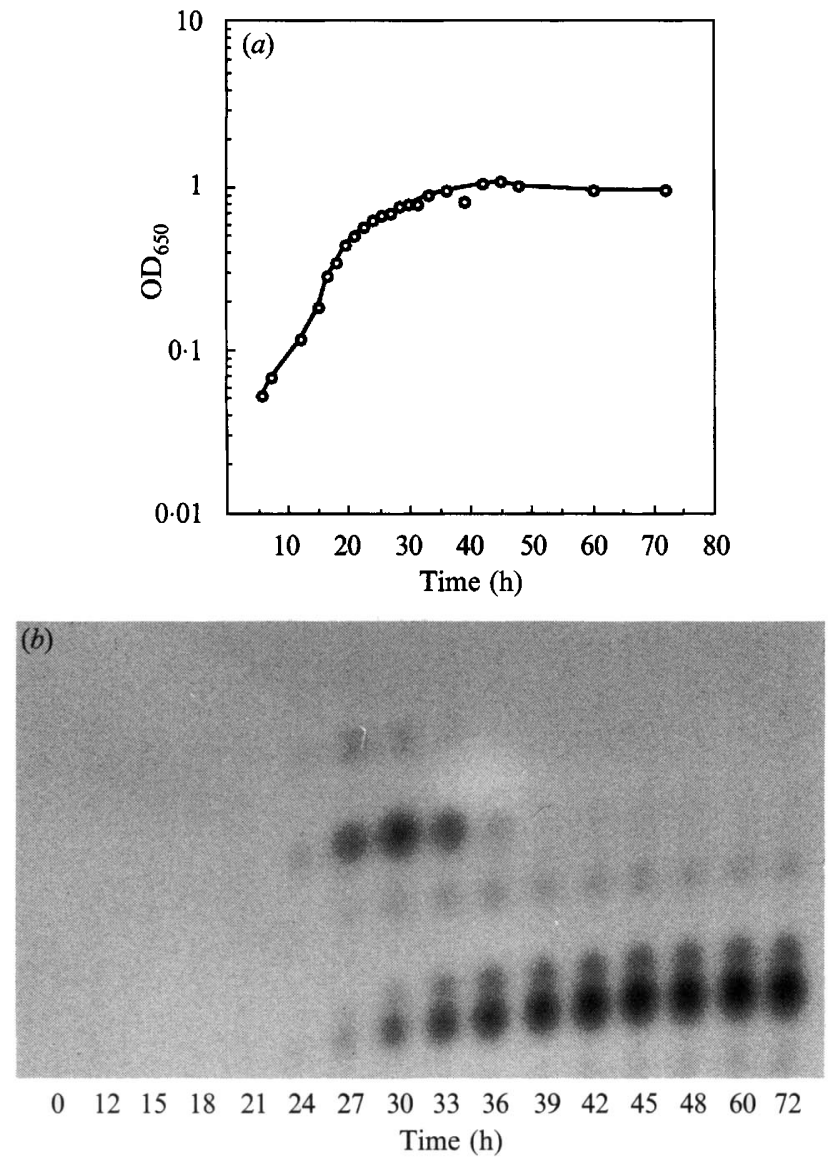

Table 2. Characteristics of thaxtomin compounds produced by $S$. scabies in oatmeal broth

\begin{tabular}{ccc}
\hline \hline Compound & $\begin{array}{c}\text { Silica gel } \\
{R_{F}{ }^{*}}^{*}\end{array}$ & $\begin{array}{c}\text { Molecular } \\
\text { mass } \dagger\end{array}$ \\
\hline 1 & $0 \cdot 31$ & 438 \\
2 & 0.33 & 438 \\
3 & $0 \cdot 40$ & 392 \\
4 & 0.46 & 422 \\
5 & 0.50 & 406 \\
\hline
\end{tabular}

${ }^{*}$ Extracts were separated by silica gel TLC in chloroform/methanol $(9: 1)$.

$\dagger$ Determined by FAB mass spectroscopy.

and potato slices (Table 1), the extract from the oatmeal broth growth medium was yellow.

To monitor phytotoxin production during growth, culture filtrate samples were taken at various times during the growth cycle for compound extraction. Equivalent volumes of each sample were analysed by silica gel TLC (Fig. 2). No yellow-pigmented compounds were detected in culture filtrates of exponentially growing cells. However, when the culture reached late exponential to early stationary phases of growth (24 to $33 \mathrm{~h}$ ), five yellow compounds were visible on the TLC plate.
Compound 5

Compound 4

Compound 3

Compound 2

Compound 1

The five yellow compounds had similar $R_{F}$ values on silica gel TLC to five thaxtomins which were recently identified from a pathogenic strain of $S$. scabies grown on sterile potato slices (Table 2) (King et al., 1992). Two of the yellow-pigmented compounds with $R_{F}$ values of 0.46 and 0.50 (compounds 4 and 5), were the first compounds to be detected, after $24 \mathrm{~h}$ culture growth. Compounds 1 and 2 were not visible at $24 \mathrm{~h}$ growth, but appeared in the $27 \mathrm{~h}$ culture and increased in intensity during the stationary phase. Compound 3 also appeared at $27 \mathrm{~h}$, and was visible throughout the stationary phase. The appearance of compounds 4 and 5 from only 24 to $36 \mathrm{~h}$ growth suggests that these compounds may be precursors in the synthesis of compounds 1 and 2 .

\section{Chemical identification of thaxtomins}

To establish the structural identity of the five yellow compounds produced by $S$. scabies grown in oatmeal broth medium, the compounds were purified by silica gel TLC, reverse-phase $\mathrm{C}_{18}$ TLC and reverse-phase $\mathrm{C}_{18}$ HPLC. The molecular masses of the five compounds were determined by FAB mass spectroscopy (Table 2). Electron impact mass spectroscopy and proton NMR analysis confirmed that the structures of these com- 
pounds were identical to the group of five thaxtomins (compounds 1-5) recently reported by King et al. (1992). The results indicate that $S$. scabies does not need to grow on the potato tuber per se in order to produce thaxtomins. Compound 1 (thaxtomin A) was the major product produced by $S$. scabies RB2 when grown on oatmeal (about $4 \mathrm{mg}$ (g cell dry wt) ${ }^{-1}$, Fig. 2); this was the major compound produced by $S$. scabies grown on potato slices (King et al., 1992; this study). King et al. (1992) reported that very little compound 3 was produced by $S$. scabies on potato slices, but sufficient amounts were produced by $S$. scabies RB2 in oatmeal broth medium for isolation and characterization.

\section{Regulation of thaxtomin biosynthesis by S. scabies grown in oatmeal broth medium}

S. scabies RB2 was grown in oatmeal broth medium at $25,28,30$ and $32{ }^{\circ} \mathrm{C}$ to optimize conditions for phytotoxin production. The strain did not grow well at temperatures below $25^{\circ} \mathrm{C}$ or above $32^{\circ} \mathrm{C}$. The cultures of $S$. scabies were harvested $24 \mathrm{~h}$ after the cells had gone into stationary phase at each temperature. Cell filtrates were extracted, and the amount of thaxtomin A produced ( $\mathrm{g}$ cell dry $\mathrm{wt})^{-1}$ was measured. The optimal temperature for production of thaxtomins was determined to be $28^{\circ} \mathrm{C}$ (data not shown). Production of thaxtomin A by S. scabies at $28{ }^{\circ} \mathrm{C}$ was $26 \%$ higher than production at $25^{\circ} \mathrm{C}, 11 \%$ higher than production at $30^{\circ} \mathrm{C}$, and $37 \%$ higher than when cells were grown at $32^{\circ} \mathrm{C}$.

Among streptomycetes there are many examples of secondary metabolites whose production is repressed by glucose (Demain, 1989). Since glucose was a component of media which did not support thaxtomin production by $S$. scabies, the effects of glucose on production were studied. Cultures of $S$. scabies RB2 were grown in oatmeal broth supplemented with $0,0 \cdot 1,0.2$ and $0.5 \%$ glucose $(\mathrm{w} / \mathrm{v})$ for $72 \mathrm{~h}$ at $28^{\circ} \mathrm{C}$, and the amount of thaxtomin A in each extract was quantified by HPLC. With $0.5 \%$ glucose, there was a 130 -fold reduction in thaxtomin production compared to the control culture grown without the addition of glucose (data not shown). Even the addition of $0.1 \%$ and $0.2 \%$ glucose to oatmeal broth medium reduced phytotoxin production by $13 \%$ and $38 \%$, respectively. The repressing levels of glucose in the agar media tested previously (Table 1) may explain the lack of phytotoxin production by $S$. scabies when grown under these conditions.

The structure of the thaxtomins led us to speculate that the biosynthesis of these compounds may require aromatic amino acids as substrates or that biosynthesis may depend on early steps in the aromatic amino acid biosynthetic pathway. To address this possibility,
Table 3. Effect of amino acid addition on thaxtomin production

\begin{tabular}{lc}
\hline \hline Addition* & $\begin{array}{c}\text { Thaxtomin A } \\
\text { production } \dagger\end{array}$ \\
\hline None & $1 \cdot 0$ \\
Alanine & $1 \cdot 0$ \\
Tryptophan & $0 \cdot 11$ \\
Tyrosine & 0.28 \\
\hline \hline
\end{tabular}

* Duplicate cultures of $S$. scabies RB2 were grown in oatmeal broth, either unsupplemented or supplemented with the indicated amino acid at $2.5 \mathrm{~mm}$, for $72 \mathrm{~h}$ at $28^{\circ} \mathrm{C}$.

$\dagger$ The amount of thaxtomin $\mathrm{A}$ in each extract was determined by HPLC, corrected for culture dry wt, and expressed relative to production in the control culture.

$2.5 \mathrm{~mm}$-tyrosine or tryptophan were added to the oatmeal broth medium to assess their effect on thaxtomin biosynthesis. These amino acids were found to significantly inhibit biosynthesis of thaxtomin A (Table 3 ). The addition of $2.5 \mathrm{~mm}$-alanine, however, did not affect thaxtomin synthesis, indicating that inhibition was not a general effect of amino acid addition to the culture. When $2.5 \mathrm{~mm}$-ammonium hydroxide was added to the oatmeal broth, thaxtomin production was not inhibited (data not shown), indicating that the inhibition caused by tyrosine and tryptophan was not due to the increased nitrogen levels but rather to a specific effect of these two amino acids on thaxtomin production. When the amino acids or ammonia concentrations in the oatmeal broth were increased to $10 \mathrm{~mm}$ or above, thaxtomin synthesis was strongly inhibited (data not shown). These results indicate a negative effect of nitrogen on thaxtomin production, consistent with the observed inhibitory effects of nitrogen on the production of some secondary metabolites (Shapiro, 1989).

\section{Discussion}

Thaxtomins are phytotoxins produced by $S$. scabies that may play a central role in inducing scab lesion formation on the tuber. A study by King et al. (1991) has shown that all pathogenic strains of $S$. scabies tested produced thaxtomins. This correlation of thaxtomin production with pathogenicity has prompted us to study the regulation of thaxtomin biosynthesis. Our studies have shown that growth of the pathogen on potato is not required for production of phytotoxin by $S$. scabies. Oatmeal agar medium supported production of phytotoxins by the pathogen, whereas no production of phytotoxin could be detected when the organism was grown on the other media tested. It is interesting to note that the nutritional composition of potato and oatmeal are very similar (USDA, 1982; USDA, 1984). There may 
be common components of oatmeal and potato which support production of phytotoxins by $S$. scabies.

We have demonstrated that all five of the reported thaxtomins (King et al., 1992) were secreted by S. scabies grown on oatmeal broth medium. The chemical structures of these compounds were confirmed by FAB mass spectroscopy and proton NMR. The production of these phytotoxins during the late exponential and early stationary phases of growth is consistent with the expression of secondary metabolites by other species of Streptomyces as well as the production of phytotoxins by certain other bacteria. For example, syringomycin, produced by Pseudomonas syringae pv. syringae, is a phytotoxin associated with numerous diseases of dicots and monocots. This phytotoxin is produced in synthetic medium by the bacteria as the culture reaches the stationary phase of growth (Gross, 1985), similar to phytotoxin production by $S$. scabies. Not all phytotoxic secondary metabolites, however, are produced solely during the stationary phase of growth. Phaseolotoxin, a phytotoxin associated with halo-blight of bean, is produced constitutively during growth by Pseudomonas syringae pv. phaseolicola (Nuske \& Fritsche, 1989).

The same five phytotoxins are produced by $S$. scabies when grown on either potato slices (King et al., 1992) or in oatmeal broth (this study). There are several advantages, however, to studying thaxtomin biosynthesis in the liquid oatmeal broth medium compared to studying thaxtomin production when $S$. scabies is grown on potato. The oatmeal medium is easier to prepare, and the bacteria grow faster in this medium than on potato slices. The isolation and purification of thaxtomins from cell filtrates is much easier, since there are fewer compounds co-isolated with thaxtomins in initial extractions. The timing of appearance of the five compounds relative to each other during the different growth stages of the culture can be monitored to suggest potential intermediates in the thaxtomin biosynthetic pathway. Another advantage to studying biosynthesis of these compounds on a synthetic medium is the opportunity to study the regulation of biosynthesis.

Differential production of these five compounds during growth (Fig. 2) of $S$. scabies led us to propose a pathway for the latter stages of thaxtomin biosynthesis (Fig. 3). Compound 3 is the logical precursor for the synthesis of the other four compounds since it is the least modified of the compounds and was detected early in stationary phase. Compounds 4 and 5 were also detected early in stationary phase, but the levels of these compounds quickly declined when compounds 1 and 2 were detected. Compound 5 would be the product of an $\mathrm{N}$-methylation in the dioxopiperazine ring of compound 3. Compound 5 is converted to compound 4 by a hydroxylation at the $\mathrm{C}-14$ position. Unlike compounds 4
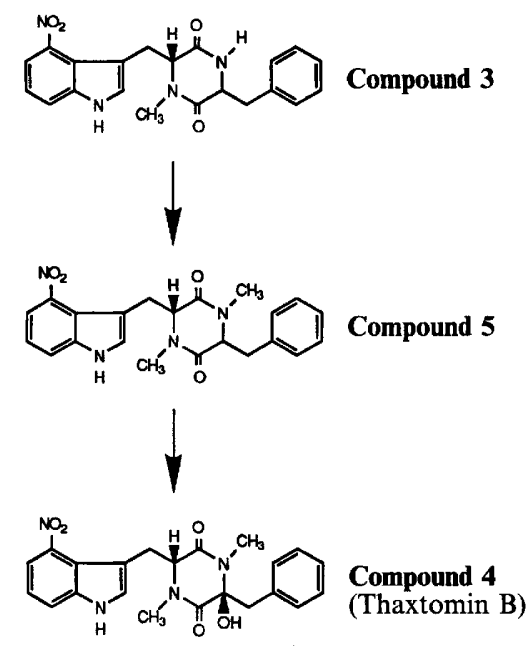

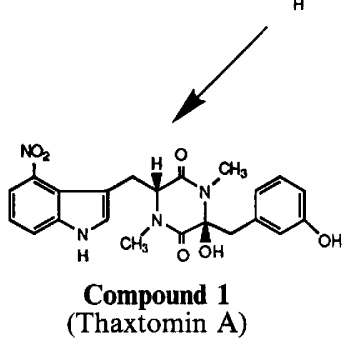

$80 \%$
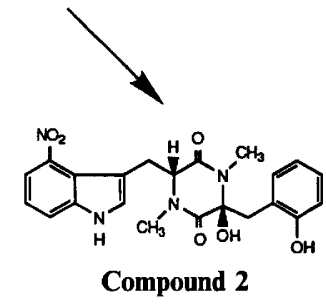

$20 \%$
Fig. 3. Proposed pathway for the later stages of thaxtomin biosynthesis. The relative amounts of compounds 1 and 2 produced in the later stages of growth were determined by comparing the areas of their HPLC elution peaks.

and 5, we have consistently detected low level amounts of compound 3 throughout stationary phase. The presence of low levels of compound 3 may be due to cleavage of the N-methyl and hydroxyl groups from the other compounds at a low frequency or to the inability of the enzyme involved in the methylation of compound 3 to convert all of the substrate to compound 5 .

As the levels of compounds 4 and 5 declined, compounds 1 and 2 were accumulated. These steps involve the hydroxylation of compound 4 at the C-19 position (compound 1) or at the $\mathrm{C}-20$ position (compound 2). Compound 1 (thaxtomin A) was the major product detected under all growth conditions tested, similar to what we found when $S$. scabies RB2 was grown on potato slices. The hydroxylation of compound 4 may either involve two enzymes which are specific for hydroxylation at the ortho or meta positions or one enzyme which is not as specific.

Thaxtomin production in oatmeal broth medium was subject to the glucose repression which has been observed for many of the secondary metabolites produced by streptomycetes (Demain, 1989). Since levels as low as $0.1 \%$ glucose will repress production of these compounds, any medium with glucose as its carbon source 
would likely not support production. These results may explain why phytotoxin production by $S$. scabies grown on synthetic media was not detected in previous studies (Lawrence et al., 1990) or in the other growth media tested in this study (Table 1).

Repression of phytotoxin production by glucose is consistent with the $S$. scabies micro-environment. $S$. scabies infects the potato through newly formed lenticels or wounds, but does not invade through intact skin (Davis \& Garner, 1978; Adams, 1975). S. scabies infection occurs early in tuber development, during which time the level of glucose in the potato peel is less than $0.1 \%$ (Goto, 1981). This non-repressive level of glucose would allow phytotoxin production by $S$. scabies during the early stages of infection. Subsequent damage to the potato tissue by the phytotoxin may increase ability of the pathogen to invade the potato and may provide nutrients for bacterial growth. In streptomycetes, the mechanism of glucose repression of secondary metabolite production is not well understood, and apparently does not involve cAMP (Demain, 1989).

The structure of thaxtomin is similar to the aromatic amino acids. We have demonstrated that thaxtomin biosynthesis was inhibited by the addition of tryptophan or tyrosine to the oatmeal broth medium. If these amino acids were simply substrates for biosynthesis we might expect that their addition would increase the production of thaxtomin. However, thaxtomin biosynthesis was inhibited by millimolar tyrosine or tryptophan. The $2.5 \mathrm{~mm}$ concentrations of these amino acids inhibiting thaxtomin biosynthesis are comparable to those which inhibit synthesis of 3-deoxy-D-arabino-heptulosonate-7phosphate synthase in Escherichia coli cultures (Brown \& Doy, 1963; Smith et al., 1962). This enzyme carries out the initial step of the shikimate pathway leading to aromatic amino acid biosynthesis. However, it has been proposed that unlike $E$. coli and other enterics, aromatic amino acid biosynthesis in the streptomycetes is regulated by growth rate rather than feedback repression (Hood et al., 1992). If aromatic amino acid biosynthesis in S. scabies is not regulated by endproduct repression, then inhibition of thaxtomin biosynthesis by these aromatic amino acids must occur through another route. One possibility is that the aromatic amino acid precursors required for thaxtomin production are synthesized by a dedicated pathway regulated by feedback inhibition. Alternatively, a branch of the aromatic amino acid pathway which is specific for thaxtomin production may itself be feedback-regulated by aromatic amino acids.

In this study we have demonstrated that milligram quantities of thaxtomin A can be readily produced and purified. The ability to produce these compounds in large quantities provides the means for studying thaxtomin A biosynthesis and for potentially using thaxtomin A application as a screen to test potato cultivars for resistance to scab disease.

This work was supported by a grant from the National Science Foundation (DMB-9111205). We would like to thank Dr Neil Anderson for his continued collaboration and critical reading of the manuscript, Tom Krick for his expert help with the MS and proton NMR analysis, and Dr R. R. King for communicating data prior to publication.

\section{References}

Adams, M. J. (1975). Potato tuber lenticels: development and structure. Annals of Applied Biology 79, 265-273.

Archula, J. R. \& Easton, G. D. (1981). The cause of deep-pitted scab of potatoes. American Potato Journal 51, 35-43.

Brown, K. D. \& Doy, C. H. (1963). End-product regulation of the general aromatic pathway in Escherichia coli W. Biochimica et Biophysica Acta 77, 170-172.

Davis, J. R. \& GARNER, J. (1978). Common Scab of Potato. University of Idaho Agriculture Experiment Station. Current Information Series, no. 386.

DEMAIN, A. L. (1989). Carbon source regulation of idiolite biosynthesis in actinomycetes. In Regulation of Secondary Metabolism in Actinomycetes, pp. 127-134. Edited by S. Shapiro. Boca Raton, Florida: CRC Press.

GoTo, K. (1981). The relationship between common scab severity and reducing sugar contents in the peel of potato tubers. Potato Research 24, 171-176.

Gross, D. C. (1985). Regulation of syringomycin synthesis in Pseudomonas syringae pv. syringae and defined conditions for its production. Journal of Applied Microbiology 58, 167-174.

HARRison, M. D. (1962). Potato russet scab, its cause and factors affecting its development. American Potato Journal 39, 368-387.

Hood, D. W., Heidstra, R., Swoboda, U. K. \& Hodgson, D. A. (1992). Molecular genetic analysis of proline and tryptophan biosynthesis in Streptomyces coelicolor A3(2): interaction between primary and secondary metabolism - a review. Gene 115, 5-12.

Hooker, W. J. (1981). Common scab. In Compendium of Potato Diseases, pp. 33-34. Edited by W. J. Hooker. St. Paul, MN: American Phytopathological Society.

Hopwood, D. A., BibB, M. J., Chater, K. F., Kieser, T., Bruton, C. J., Kieser, H. M., Lydiate, D. J., Smith, C. P., Ward, J. M. \& SCHREMPF, H. (1985). Genetic Manipulation of Streptomyces-a Laboratory Manual. Norwich, UK: The John Innes Foundation.

King, R. R., Lawrence, C. H., Clark, M. C. \& Calhoun, L. A. (1989). Isolation and characterization of phytotoxins associated with Streptomyces scabies. Journal of the Chemical Society (London) 13, 849-850.

King, R. R., LAWrence, C. H. \& Clark, M. C. (1991). Correlation of phytotoxin production with pathogenicity of Streptomyces scabies isolates from scab infected potato tubers. American Potato Journal 68, 675-680

King, R. R., Lawrence, C. H. \& Calhoun, L. A. (1992). Chemistry of phytotoxins associated with Streptomyces scabies, the causal organism of potato common scab. Journal of Agricultural Food Chemistry 40, 834-837.

KolattukUdy, P. E. (1980). Biopolyester membranes of plants: cutin and suberin. Science 208, 990-999.

KolatTukUdy, P. E. (1981). Structure, biosynthesis and biodegradation of cutin and suberin. Annual Review of Plant Physiology 32, 539-567.

KolatTUKUDY, P. E. (1984). Biochemistry and function of cutin and suberin. Canadian Journal of Botany 62, 2918-2933.

LAMBert, D. H. \& LoRIA, R. (1989). Streptomyces scabies sp. nov., nom. rev. International Journal of Systematic Bacteriology 39, 387-392.

LAUER, F. I. (1977). Tubers from leaf-bud cuttings: a tool for potato seed certification and breeding. American Potato Journal 54, 457-464. Lawrence, C. H., Clark, M. C. \& King, R. R. (1990). Induction of 
common scab symptoms in aseptically cultured potato tubers by the vivotoxin, thaxtomin. Phytopathology 80, 606-608.

Murashige, T. \& Skoog, F. (1962). A revised medium for rapid growth and bioassays with tobacco tissue cultures. Physiologia Plantarum 15, 473.

NuSKE, J. \& FRITSCHE, W. (1989). Phaseolotoxin production by Pseudomonas syringae pv. phaseolicola: the influence of temperature. Journal of Basic Microbiology 29, 441-447.

SHAPIRO, S. (1989). Nitrogen assimilation in actinomycetes and the influence of nitrogen nutrition on actinomycete secondary metabolism. In Regulation of Secondary Metabolism in Actinomycetes, pp. 135-211. Edited by S. Shapiro. Boca Raton, Florida: CRC Press.

ShIRLING, E. B. \& GotTLIEB, D. (1966). Methods of characterization of Streptomyces species. International Journal of Systematic Bacteriology 16, 313-340.
SLACK, S. A. (1992). A look at potato leafroll virus and PVY: past, present and future. Valley Potato Grower 57, 35-39.

SMith, L. C., Ravel, J. M., LaX, S. R. \& ShIVE, W. (1962). The control of 3-deoxy-D-arabino-heptulosonic acid 7-phosphate synthesis by phenylalanine and tyrosine. Journal of Biological Chemistry 237, 3566-3570.

United States Department of Agriculture: Agriculture Science AND EDUCATION ADMinistration (1982). Composition of foods: breakfast cereals, raw, processed and prepared. In Agriculture Handbook No. 8-8, pp. 137-138. Washington DC: United States Government Printing Office.

United States Department of Agriculture: Human Nutrition INFORMATION SERVICE (1984). Composition of foods: vegetables and vegetable products: raw, processed and prepared. In Agriculture Handbook No. 8-11, pp. 294-295. Washington DC: United States Government Printing Office. 